\title{
A district benzodiazepine policy in practice
}

\author{
Prescribing changes over 19 months
}

\author{
D. G. RAmster, Consultant Psychiatrist; and A. J. BARBer, Principal Pharmacist, \\ Severalls Hospital, Boxted Road, Colchester, Essex
}

It was decided to plan the introduction of a benzodiazepine policy in North East Essex when the result of a health authority survey of all local general practitioners in 1986 revealed a substantial dependence problem among patients in the area.

Out of the 215 GPs circulated, 211 replied to a questionnaire and $76 \%$ reported by their own definition 1518 cases of dependence. Of the GPs, $60 \%$ felt that there was a need for counselling and support groups for those abusing or addicted to benzodiazepines. GPs were encouraged to write about their experiences of the problems, and remarks ranged from "Every long-term user is potentially an addict" to "Should treatment for social stress be treated as an addiction".

Two guiding principles were used in the formulation of the policy; first to limit the prescribing of benzodiazepines to short-term use and secondly to inform the patient of the nature of the drug being prescribed. In addition it was recommended that the use of lorazepam should be avoided as there were reports of more difficult withdrawal symptoms following its use. (Drugs and Therapeutics Bulletin, 1985).

A policy was presented to the District Drugs and Therapeutics Committee in October 1987 (Ramster, 1987a; 1987b). It was duly accepted as the district's policy and circulated to all medical practitioners. Hospital prescriptions which did not accord with the policy were not automatically dispensed by the pharmacy but were discussed with prescribing doctor.

One important development from this policy was the production of a patient information leaflet. The leaflet attempts to explain the acute and chronic side effects of benzodiazepines and places emphasis on the dangers of concurrent consumption of alcohol. The risk of dependence is explained and typical withdrawal symptoms are described. The leaflet goes on to offer advice on how patients can take their medicines more safely. The leaflets are being distributed to both short-term and chronic users of benzodiazepines, through hospital and community pharmacies. Although there has been some resistance from local
GPs, the overall response has been favourable and some local doctors are even using the leaflets in their own practices. The leaflet is illustrated and was produced by the authors.

\section{Patient Information Leaflet}

This leaflet contains important information and advice about the medicine you have been given.

\section{WHAT HAVE I BEEN GIVEN?}

You have been given ......, a medicine which is safe and effective when used correctly. This medicine or others like it, are known as benzodiazepines. They are used in the treatment of anxiety or insomnia (difficulty in sleeping) and are often referred to as tranquillisers or sleeping tablets.

\section{DO THEY HAVE ANY SIDE EFFECTS?}

Like all medicines they may have some unwanted effects in some patients. They may cause dizziness or sleepiness, which can make driving or using machinery dangerous, particularly when first starting treatment. Alcohol will make this worse so try not to drink any. Sleeping tablets (or capsules) may still produce these effects the morning after you take the medicine.

Benzodiazepines can be habit forming if taken every day for a long time (for more than one or two months). It can then become difficult to do without the medicine as your body has become used to it.

If you stop taking it suddenly, you may suffer unpleasant withdrawal effects such as anxiety, irritability, restlessness and difficulty in sleeping. These are not dangerous.

IN ORDER TO USE THIS MEDICINE SAFELY WITH THE LEAST CHANCE OF EXPERIENCING SIDE EFFECTS, PLEASE FOLLOW THE ADVICE GIVEN.

\section{TAKING YOUR MEDICINE SAFELY}

If this is your first prescription for a benzodiazepine make sure you see your Doctor before getting any more.

If you are a regular user of benzodiazepines then you may wish to make an appointment with your doctor to discuss alternative help or ways of withdrawing the medication slowly that will avoid withdrawal symptoms.

If you are being treated for insomnia, try to avoid taking the medicine every night, leave two or three nights each 
week medicine free. This will reduce the chance of it becoming a habit. It may also be helpful to avoid caffeinecontaining drinks, such as coffee and tea before going to bed.

Don't use them for long periods. Don't stop medicines suddenly.

Don't drink alcohol in the daytime, particularly when first starting treatment. If you normally like a drink in the evening with your meal or before going to bed, then it will normally be safe to have a small amount.

Benzodiazepines can help in the short term to relieve symptoms such as anxiety and insomnia, but they are not a long term answer to the stresses of life. For any further information on the medicine you have been prescribed, ask your doctor or pharmacist.

\section{Findings}

Tables I and II are a record of benzodiazepine tablets and capsules issued from the three Acute Unit Pharmacies and the Mental Health Unit Pharmacy, since January 1987. For simplicity, only the most popular drugs are shown in the tables; other benzodiazepines, such as triazolam, amount to less than 500 tablets issued per quarter.
The Acute Unit Pharmacies supply 780 surgical, medical, maternity, geriatric beds, 775 mental handicap beds and 280 beds in outlying community hospitals. The Mental Health Unit Pharmacy supplies 543 in-patients' psychiatric beds, 130 day places and 98 acute medical and surgical beds. The two pharmacies therefore supply mixed needs. However, benzodiazepine use was predominantly either by acute medical or surgical wards in the acute sector or by the mental illness unit in the Mental Health sector.

Separate figures are shown for the out-patient and in-patient use of temazepam. Overall there has been a reduction in benzodiazepine use. The extent of the fall in the use varies between the different compounds and the different departments. The greatest fall has been in the prescribing of lorazepam as recorded by the Mental Health Unit. The use of lorazepam in the last quarter (July to September 1988) was less than one third of the amount prescribed in the same period last year.

Diazepam $2 \mathrm{mg}$ has been increasingly prescribed to wean patients from higher dose tablets or from lorazepam.

District benzodiazepines issues: Numbers of units dispensed (capsules and tablets) (adjusted to the nearest 10)

TABLE I

Acute Unit

\begin{tabular}{lcccccc}
\hline & Lorazepam & $\begin{array}{c}\text { Temazepam } \\
\text { (Out-patient) } \\
1 \mathrm{mg}\end{array}$ & $\begin{array}{c}\text { Temazepam } \\
\text { (In-patient) } \\
10 \mathrm{mg}\end{array}$ & $\begin{array}{c}\text { Diazepam } \\
2 \mathrm{mg}\end{array}$ & $\begin{array}{c}\text { Diazepam } \\
5 \mathrm{mg}\end{array}$ & $\begin{array}{c}\text { Nitrazepam } \\
5 \mathrm{mg}\end{array}$ \\
\hline Jan-Mar (1987) & 1,720 & 3,080 & 28,130 & 6,530 & 7,780 & 5,630 \\
Apr-Jun & 1,600 & 3,120 & 27,750 & 7,540 & 7,370 & 4,980 \\
July-Sept & 1,460 & 2,800 & 25,700 & 7,010 & 7,850 & 5,390 \\
Oct-Dec* & 1,360 & 2,770 & 24,650 & 6,930 & 7,490 & 5,480 \\
- Jan-Mar(1988) & 1,400 & 2,180 & 23,700 & 7,150 & 5,960 & 5,550 \\
Apr-Jun & 1,410 & 2,030 & 22,150 & 5,930 & 4,910 & 3,920 \\
July-Sept & 1,530 & 2,040 & 18,950 & 6,800 & 4,830 & 4,450 \\
\hline
\end{tabular}

TABLE II

Mental Health Unit

\begin{tabular}{lcccccc}
\hline Jan-Mar (1987) & 3,380 & 5,450 & 7,986 & 2,290 & 3,390 & 2,500 \\
Apr-Jun & 3,910 & 4,660 & 8,000 & 3,060 & 3,880 & 2,300 \\
July-Sept & 3,310 & 5,680 & 6,550 & 5,610 & 3,670 & 1,920 \\
Oct-Dec* & 2,790 & 4,680 & 6,200 & 3,280 & 3,240 & 1,610 \\
\hline$--1,-000$ & 4,430 & 6,250 & 2,560 & 2,910 & 1,670 \\
Jan-Mar (1988) & 2,010 & 4,470 & 5,600 & 3,780 & 2,820 & 1,260 \\
Apr-Jun & 1,460 & 4,160 & 3,800 & 3,760 & 2,490 & 880 \\
July-Sept & 1,000 & & & & & \\
\hline
\end{tabular}

*District benzodiazepine policy accepted 6 October 1987. 
There has been no concurrent increase in the use of non-benzodiazepine hypnotics such as chloral hydrate or chlormethiazole; drugs which have their own particular problems.

\section{Comment}

Medical practitioners in North East Essex Hospitals agreed to a district health authority policy on the prescribing of benzodiazepines. An original feature of the policy was the collaboration between hospital pharmacists and medical staff to ensure that prescriptions met the guidelines.

One proposal has just recently been implemented. All out-patient and discharge benzodiazepine supplies now carry an additional label warning, "Warning, long-term use may cause dependence". Emphasis has been on changing hospital prescribing habits so that new benzodiazepine users are not created inadvertently by routine prescription of hypnotics, and in the hope that family doctors will follow hospital prescribing patterns. This spread to the community has not yet taken place. A small survey of 20 community pharmacists in the Colchester area revealed that the numbers of repeat prescriptions for benzodiazepines do not appear to be falling significantly, although some pharmacists report a fall in lorazepam prescription. This local initiative is only one of the several influences which have limited benzodiazepine use in the past year. Among the major influences are the Committee on Safety of Medicines Report in January 1988 and the Royal College of Psychiatrists Report in the Bulletin (1988).

It is hoped that all the local and national intiatives will encourage drug-free approaches to the treatment of insomnia and anxiety.

\section{References}

COMmittee on SAFETY of Medicines (1988) Benzodiazepines and dependence. Current Problems, No 21, January 1988.

DRUGS AND ThERAPEUTICS BULletin (1985) Lorazepama benzodiazepine to choose or avoid? Drugs and Therapeutics Bulletin, 23, 61-62.

RAMSTER, D. et al (1987a) A policy on benzodiazepines. The Lancet, 2, 1406. (Letter).

- (1987b) A policy on benzodiazepines. The Pharmaceutical Journal, 239, 677 (Letter).

Royal College of PsyChIATRISTs (1988) Benzodiazepines and dependence: A College statement. Bulletin of the Royal College of Psychiatrists, 12, 107-109.

Copies of the Illustrated Information Leaflet for patients are available from Colchester District General Hospital Pharmacy Department.

\section{Crichton Royal Hospital 1839-1989}

\section{R. G. McCReAdIE, Director of Clinical Research; A. C. TAIT, formerly Physician Superintendent; and MORAG Williams, Hospital Archivist; Crichton Royal Hospital, Dumfries}

On 4 June 1839 the first patient walked with friends the mile uphill to the new Crichton Institution from the lunatic wing of Dumfries and Galloway Royal Infirmary. Detailed clinical records support a diagnosis of melancholia; the patient was discharged well in 1844 and follow-up confirmed her recovery.

The hospital was founded by Mrs Elizabeth Crichton, the widow of Dr James Crichton, both Physician to the Governor General of India and trader in India and China. Mrs Crichton's first desire was to establish a fifth university in Scotland. However she was refused Government approval, largely because of lobbying by the four existing universities in Scotland, which had vacant places, were short of money, and knew that students would be attracted to a new competitor. The university thus rejected, Mrs Crichton decided a proper second choice would be a lunatic asylum.
When Crichton opened with some 120 beds it was designed mainly for paying patients but with accommodation ample enough to receive the local and other poor. It was described in the press as "surpassing everything of its kind that has yet been established in Europe". An advertisement for the institution read as follows: "Every facility will be given for the admission of individuals whose condition requires confinement, whatever their rank or means may be; and it has been determined that the maintenance, classification and general treatment shall be regulated more by what the Patients may have been accustomed to, and by what their present happiness and ultimate recovery may demand, than by the sum of money that is paid".

The first physician superintendent or 'Resident Physician' was Dr W. A. F. Browne, formerly Superintendent to the Montrose Royal Asylum; he was 